\title{
Infectious diseases in returned travellers,
}

NSW, 2010-2011

\author{
Praveena Gunaratnam $^{\mathrm{A}, \mathrm{B}, \mathrm{D}}$, Sean Tobin ${ }^{\mathrm{C}}$, \\ Holly Seale ${ }^{\mathrm{B}}$ and Jeremy M. McAnulty ${ }^{\mathrm{C}}$ \\ ${ }^{\mathrm{A}}$ NSW Public Health Officer Training Program, \\ NSW Ministry of Health \\ ${ }^{\mathrm{B}}$ School of Public Health and Community Medicine, \\ The University of NSW \\ ${ }^{\mathrm{C}}$ Health Protection NSW \\ ${ }^{\mathrm{D} C o r r e s p o n d i n g ~ a u t h o r . E m a i l: p g u n a @ d o h . h e a l t h . n s w . g o v . a u ~}$
}

Evidence from developed countries suggests that many case notifications for particular infectious diseases are associated with overseas travel. For example, a review of typhoid fever surveillance data indicated that most case notifications in developed countries are imported. ${ }^{1}$ Malaria surveillance in the United Kingdom (UK) (1987-2006) and the United States (2011) also showed a consistently high number of case notifications, all of which are believed to have been acquired overseas., ${ }^{2,3}$

Analysis of notifiable diseases data in Australia has also highlighted travel as a risk factor for a range of infections. Over half of all cases of enteric fever in Queensland from 2006 to 2008, and half of all cases of hepatitis A in New South Wales (NSW) from 2002 to 2006, had travel as a risk factor. ${ }^{4,5}$ Australia-wide in 2008 and 2009, all malaria case notifications and almost half of dengue case notifications were acquired overseas. ${ }^{6}$

The destination and reason for travel have implications for disease risk. A relationship exists between travel to an area where a particular disease is endemic and risk of that disease, with data showing that malaria diagnoses are most common in travellers to sub-Saharan Africa, while dengue diagnoses are associated with travel to South-East Asia and hepatitis E diagnoses with travel to South Asia. ${ }^{7-9}$

Also critical is the reason for travel, with travellers visiting friends and relatives (VFR) found to be at greater risk of some diseases compared to tourist travellers. For example, a UK study showed that where the reason for travel was known, $76 \%$ of malaria infections and $88 \%$ of typhoid and paratyphoid infections were acquired during VFR travel. ${ }^{10}$ Data from the GeoSentinel Surveillance database collected from 210 sites in several countries showed similar results. ${ }^{11}$

Short-term international departures (with a duration of less than 1 year) amongst NSW residents increased by $50 \%$ from 1.8 million in 2005 to 2.7 million in $2011 .^{12}$ This study sought to quantify the proportion of selected notified diseases attributable to overseas travel and to assess the quality of data on travel-associated risk factors such as place of acquisition, in order to inform the development of appropriately targeted prevention strategies.

\section{Methods}

Under the NSW Public Health Act 2010, doctors, hospitals and laboratories must notify cases of selected infectious diseases to NSW Health. Seven of these notifiable 
Table 1. Selected infectious diseases by place of acquisition, NSW, 2010-2011

\begin{tabular}{|c|c|c|c|c|c|c|c|}
\hline Place of acquisition & $\begin{array}{c}\text { Dengue } \\
N=345 \\
\text { (\%) }\end{array}$ & $\begin{array}{c}\text { HAV } \\
N=138 \\
(\%)\end{array}$ & $\begin{array}{c}\text { HEV } \\
N=35 \\
(\%)\end{array}$ & $\begin{array}{c}\text { Malaria } \\
N=196 \\
(\%)\end{array}$ & $\begin{array}{c}\text { Paratyphoid } \\
N=56 \\
(\%)\end{array}$ & $\begin{array}{c}\text { Shigellosis } \\
N=248 \\
(\%)\end{array}$ & $\begin{array}{c}\text { Typhoid } \\
N=71 \\
(\%)\end{array}$ \\
\hline Acquired in Australia & $2(0.6)$ & $41(29.7)$ & $0(0.0)$ & $0(0.0)$ & $4(7.1)$ & 79 (31.9) & $0(0.0)$ \\
\hline Acquired overseas & $342(99.1)$ & $95(68.8)$ & $31(88.6)$ & $196(100.0)$ & $52(92.9)$ & $75(30.2)$ & $71(100.0)$ \\
\hline Missing & $1(0.3)$ & $2(1.4)$ & $4(11.4)$ & $0(0.0)$ & $0(0.0)$ & 94 (37.9) & $0(0.0)$ \\
\hline
\end{tabular}

diseases - dengue, hepatitis A, hepatitis E, malaria, paratyphoid fever (excluding that which is caused by Salmonella paratyphi B Java, which is believed to be mainly locally acquired), shigellosis and typhoid fever - were chosen for analysis on the basis that: (i) a significant proportion of cases were expected to be overseas acquired; and (ii) these diseases are easily preventable and could be the target of public health action with high-risk groups.

In NSW, Public Health Unit staff investigate notified cases and record demographic, clinical and risk information in the NSW Notifiable Conditions Information Management System (NCIMS) as per response protocols for individual diseases in the NSW Notifiable Diseases Manual. ${ }^{13}$

Notification data for confirmed cases (and probable cases for hepatitis A) of each of the seven diseases with an onset date from 1 January 2010 to 31 December 2011 were exported from NCIMS and reviewed for quality and completeness. Completeness of data on travel-associated variables and the use of preventive measures was increased by cross-referencing data fields with free text information recorded in the 'Notes' field, and working with responsible PHUs to fill missing data fields where possible. Specifically, whether an infection was locally or overseas acquired was derived from the 'Import Status' data field or 'Notes' field for the majority of case notifications for all diseases.

Descriptive analyses were performed using Microsoft Excel for demographic variables (age, sex, country of birth), travel-associated variables (percentage acquired overseas or reporting recent travel, country acquired), and use of preventive measures (vaccination for hepatitis A or typhoid, anti-malarial medication). Epi-Info 7 (Centers for Disease Control and Prevention, Atlanta, USA) was used to calculate proportions and to perform $\mathrm{X}^{2}$ tests for significance for hepatitis A vaccination. Significance was set at the $5 \%$ level. Numbers for other preventive measures were too small to warrant testing for statistical significance.

Data on country of birth and country of disease acquisition were grouped into regions using the World Bank classification system, with Australia and New Zealand extracted as a separate category. ${ }^{14}$ Rates were calculated using population figures taken from Australian Bureau of Statistics (ABS) estimates and averaged over 2010 and $2011^{15}$

\section{Results}

The quality of data available on travel-associated risk factors and use of preventive measures varied by disease. Information on place of acquisition was largely complete, with the exception of shigellosis where this remained unknown for $37.9 \%$ of case notifications. Country of birth was missing for $10 \%$ or more of overseas-acquired cases with dengue, malaria, paratyphoid or shigellosis. Information on the use of prophylaxis was missing in one-third of malaria case notifications, and on use of vaccines for over $10 \%$ of hepatitis A case notifications and over $20 \%$ of typhoid fever case notifications. Reason for travel was not routinely recorded.

Case notifications for the selected diseases by place of acquisition are presented in Table 1. For case notifications where place of acquisition was known, the proportion acquired overseas ranged from $48.7 \%$ for shigellosis to $100 \%$ for hepatitis E, malaria and typhoid. Males accounted for a higher proportion of overseas-acquired infections for all diseases, from $51.5 \%$ of dengue case notifications to $68.7 \%$ of malaria case notifications. The age distribution of overseas-acquired case notifications differed by disease. Age-specific rates were highest in the 5-9 and 10-14-year age groups for hepatitis A (4.5 and 4.6 per 100000 population respectively), the 25-29-year age group for hepatitis E (1.6 per 100000 population), malaria (4.8 per 100000 population), paratyphoid (2.4 per 100000 population) and typhoid (4.4 per 100000 population) and the 30-34-year age group for shigellosis (2.4 per 100000 population).

For the majority of case notifications, the country where the disease was most likely acquired was reported (Table 2). Overseas-acquired hepatitis E, paratyphoid fever and typhoid fever were predominantly from South Asia. East and South-East Asia accounted for the largest proportion of 
Table 2. Selected infectious diseases acquired outside Australia by likely region of acquisition, NSW, 2010-2011

\begin{tabular}{|c|c|c|c|c|c|c|c|}
\hline Region of acquisition & $\begin{array}{c}\text { Dengue } \\
N=342 \\
(\%)\end{array}$ & $\begin{array}{c}\text { HAV } \\
N=95 \\
(\%)\end{array}$ & $\begin{array}{c}\text { HEV } \\
N=31 \\
(\%)\end{array}$ & $\begin{array}{c}\text { Malaria } \\
N=196 \\
(\%)\end{array}$ & $\begin{array}{c}\text { Paratyphoid } \\
\begin{array}{c}N=52 \\
(\%)\end{array}\end{array}$ & $\begin{array}{c}\text { Shigellosis } \\
\begin{array}{c}N=75 \\
(\%)\end{array}\end{array}$ & $\begin{array}{c}\text { Typhoid } \\
N=71 \\
(\%)\end{array}$ \\
\hline East and South East Asia & $269(78.7)$ & $20(21.1)$ & $5(16.1)$ & $13(6.6)$ & $5(9.6)$ & $29(38.7)$ & $7(9.9)$ \\
\hline Europe and Central Asia & $0(0.0)$ & $2(2.1)$ & $0(0.0)$ & $0(0.0)$ & $0(0.0)$ & $0(0.0)$ & $0(0.0)$ \\
\hline Latin America and Caribbean & $13(3.8)$ & $0(0.0)$ & $0(0.0)$ & $1(0.5)$ & $2(3.8)$ & $4(5.3)$ & $0(0.0)$ \\
\hline Middle East and North Africa & $0(0.0)$ & $11(11.6)$ & $0(0.0)$ & $0(0.0)$ & $1(1.9)$ & $8(10.7)$ & $1(1.4)$ \\
\hline Pacific & $9(2.6)$ & $20(21.1)$ & $1(3.2)$ & $50(25.5)$ & $0(0.0)$ & $14(18.7)$ & $8(11.3)$ \\
\hline South Asia & $48(14.0)$ & $31(32.6)$ & $24(77.4)$ & $38(19.4)$ & $43(82.7)$ & $16(21.3)$ & $55(77.5)$ \\
\hline Sub-Saharan Africa & $1(0.3)$ & $10(10.5)$ & $1(3.2)$ & $90(45.9)$ & $0(0.0)$ & $3(4.0)$ & $0(0.0)$ \\
\hline Missing & $2(0.6)$ & $1(1.1)$ & $0(0.0)$ & $4(2.0)$ & $1(1.9)$ & $1(1.3)$ & $0(0.0)$ \\
\hline
\end{tabular}

Table 3. Selected infectious diseases acquired outside Australia by region of birth, NSW, 2010-2011

\begin{tabular}{|c|c|c|c|c|c|c|c|}
\hline Region of birth & $\begin{array}{c}\text { Dengue } \\
N=342 \\
(\%)\end{array}$ & $\begin{array}{c}\text { HAV } \\
N=95 \\
(\%)\end{array}$ & $\begin{array}{c}\text { HEV } \\
N=31 \\
(\%)\end{array}$ & $\begin{array}{c}\text { Malaria } \\
N=196 \\
(\%)\end{array}$ & $\begin{array}{c}\text { Paratyphoid } \\
N=52 \\
(\%)\end{array}$ & $\begin{array}{c}\text { Shigellosis } \\
N=75 \\
(\%)\end{array}$ & $\begin{array}{c}\text { Typhoid } \\
N=71 \\
(\%)\end{array}$ \\
\hline Australia and New Zealand & $149(43.6)$ & $34(35.8)$ & $4(12.9)$ & $45(23.0)$ & $13(25.0)$ & $36(48.0)$ & $16(22.5)$ \\
\hline East and South East Asia & $29(8.5)$ & $12(12.6)$ & $3(9.7)$ & $3(1.5)$ & $3(5.8)$ & $1(1.3)$ & $4(5.6)$ \\
\hline Europe and Central Asia & $16(4.7)$ & $3(3.2)$ & $1(3.2)$ & $6(3.1)$ & $3(5.8)$ & $4(5.3)$ & $1(1.4)$ \\
\hline Latin America and Caribbean & $1(0.3)$ & $0(0.0)$ & $0(0.0)$ & $0(0.0)$ & $0(0.0)$ & $2(2.7)$ & $0(0.0)$ \\
\hline Middle East and North Africa & $1(0.3)$ & $9(9.5)$ & $2(6.5)$ & $1(0.5)$ & $2(3.8)$ & $1(1.3)$ & $0(0.0)$ \\
\hline North America & $1(0.3)$ & $0(0.0)$ & $0(0.0)$ & $0(0.0)$ & $0(0.0)$ & $0(0.0)$ & $0(0.0)$ \\
\hline Pacific & $1(0.3)$ & $5(5.3)$ & $0(0.0)$ & $10(5.1)$ & $1(1.9)$ & $3(4.0)$ & $7(9.9)$ \\
\hline South Asia & $24(7.0)$ & $23(24.2)$ & $21(67.7)$ & $32(16.3)$ & $23(44.2)$ & $1(1.3)$ & $39(54.9)$ \\
\hline Sub-Saharan Africa & $2(0.6)$ & $4(4.2)$ & $0(0.0)$ & $59(30.1)$ & $0(0.0)$ & $2(2.7)$ & $0(0.0)$ \\
\hline Missing & $118(34.5)$ & $5(5.3)$ & $0(0.0)$ & $40(20.4)$ & $6(11.5)$ & $25(33.3)$ & $4(5.6)$ \\
\hline
\end{tabular}

imported dengue and shigellosis case notifications, with almost half of dengue case notifications being acquired in Indonesia in particular. Just under half of malaria infections were acquired in sub-Saharan Africa, with another quarter acquired in the Pacific.

The proportion of overseas-acquired diseases by country of birth, where information on country of birth was available, is presented in Table 3. At least half of overseas-acquired hepatitis E, paratyphoid and typhoid fever infections, where country of birth was known, were in people born in South Asia, while over one-third of malaria cases were born in sub-Saharan Africa.

For overseas-acquired diseases where country of birth was known, over half of hepatitis A $(53.3 \%)$, hepatitis E $(74.2 \%)$, malaria $(54.5 \%)$, paratyphoid $(53.3 \%)$ and typhoid $(65.7 \%)$ cases were associated with travel to, and disease acquisition in, the person's country of birth. Dengue and shigellosis cases were more likely to be born in Australia or New Zealand, so the proportion of case notifications associated with travel to country of birth was lower, at $22.3 \%$ and $10.0 \%$ respectively.

The proportion of cases requiring hospitalisation was high for typhoid $(94.2 \%)$, malaria $(60.6 \%)$ and hepatitis $\mathrm{E}$ (67.7\%), and lower but still substantial for hepatitis A $(41.9 \%)$, dengue $(34.6 \%)$ and shigellosis $(24.0 \%)$. Hospitalisation was uncommon for paratyphoid fever $(0.8 \%)$.

Information on vaccination status was available for 121 (87.7\%) hepatitis A cases and 55 (77.5\%) typhoid cases. For hepatitis A, both locally and overseas-acquired cases were unlikely to be vaccinated, however locallyacquired cases $(22.2 \%)$ were significantly more likely than overseas-acquired cases $(4.8 \%)$ to have received at least one dose of the hepatitis A vaccine $\left(\mathrm{X}^{2}=6.58, p<0.02\right)$. For typhoid, $92.9 \%$ of cases - all overseas acquired - had not been vaccinated.

Information on the use of chemoprophylaxis was available for $147(75.0 \%)$ malaria cases. Of these, $27(67.5 \%)$ 
Australian and New Zealand-born cases reported using chemoprophylaxis, compared to 45 (50.5\%) cases born in other countries. Information on the extent to which chemoprophylaxis was used correctly was unavailable.

\section{Discussion}

This study confirms that a large number of selected enteric and vectorborne disease case notifications are associated with overseas travel. Males and travellers in the 25-34-year age group are most likely to be affected. Australia-wide data suggests these are also the groups most likely to travel. ${ }^{16}$ Uptake of vaccination was poor amongst typhoid fever and hepatitis A cases, and use of chemoprophylaxis for malaria was low, particularly among cases born outside Australia or New Zealand.

Similar to other studies, this analysis indicates that case notifications of hepatitis A, hepatitis E, paratyphoid and typhoid are strongly associated with return to the person's country of birth in South Asia, and case notifications of malaria with return to the person's country of birth in subSaharan Africa. Visiting friends and family is a likely reason for travel in these instances. Dengue and shigellosis case notifications are perhaps more likely found among tourists and other types of travellers but existing surveillance information cannot illustrate this definitively. A recent review of typhoid fever case notifications in NSW found information on reason for travel available in the 'Notes' field in NCIMS, but this is limited and cannot be used to assess if VFR travellers in NSW are at significantly higher risk than other types of travellers. ${ }^{17}$

Reason for travel is important as VFR travellers have specific risk factors. These include longer stays, incomplete childhood vaccination, not seeking pre-travel advice and not taking appropriate preventive measures such as chemoprophylaxis. ${ }^{18-21}$ While overseas, they may also adopt the practices of the local community such as drinking untreated water, or not perceive themselves to be at risk due to the familiarity of the surroundings. ${ }^{18-20}$

All people travelling to endemic areas should be made aware of the risks and encouraged to take preventive measures. For foodborne and waterborne diseases, these measures include vaccination for hepatitis A and typhoid, only using boiled or bottled water, not eating uncooked foods, and washing hands thoroughly after going to the toilet and before eating. For vectorborne diseases, chemoprophylaxis where appropriate should be taken (for malaria), and mosquito bites avoided through the use of insect repellent (for dengue and malaria). ${ }^{22,23}$ Sleeping under bed nets at night is also recommended to avoid malaria. ${ }^{23}$

There are several limitations to this study. Firstly, there was a substantial amount of missing data on travelassociated risk factors, particularly for dengue, malaria and shigellosis. Country of acquisition was missing for over one-third of shigellosis case notifications, though shigellosis follow-up became mandatory for Public Health Units in 2012, which should improve completeness. Of cases known to be overseas acquired, country of birth was missing for $34.5 \%$ of dengue case notifications, $20.4 \%$ of malaria case notifications and $33.3 \%$ of shigellosis case notifications.

Data on vaccination status and use of malaria chemoprophylaxis were incomplete, and available information was based on self-report, which can be unreliable. Data on vaccination amongst hepatitis A case notifications particularly should be interpreted with caution as vaccine failures are rare, and misreporting or confusion about vaccination status possible. ${ }^{22}$

Finally, information on reason for travel is not routinely collected. Assuming return to country of birth is associated with VFR travel is a proxy measure for the number of case notifications associated with this reason for travel, but incorrectly excludes people who may be born in Australia but travel to a country of their ethnic origin for VFR purposes, and includes people who return to their country of birth for another reason, such as business.

Improved completeness of data is required before routine surveillance can be used to reliably monitor trends in disease importation or target particular communities which may be at risk. Enhanced surveillance, periodic studies and/or targeted surveys could also gather information on the association between reason for travel and disease risk, risk perception and risk behaviours, and barriers to the use of preventive measures. With this information it may be possible to develop novel strategies to reduce the incidence of these important travel-acquired infections among NSW residents.

\section{Conclusion}

A large proportion of selected enteric and vectorborne disease case notifications in NSW are associated with overseas travel. Improvements in data on risk factors, reason for travel and barriers to the use of preventive measures would better inform targeted prevention strategies.

\section{Acknowledgments}

This work was completed while Praveena Gunaratnam was a trainee on the NSW Public Health Officer Training Program, funded by the NSW Ministry of Health. She undertook this work while based the Communicable Diseases Branch, Health Protection NSW. Thanks to Jennie Musto and Paula Spokes from Health Protection NSW for offering comments on the paper.

\section{References}

1. Connor BA, Schwartz E. Typhoid and paratyphoid fever in travellers. Lancet Infect Dis 2005; 5(10): 623-8. doi:10.1016/ S1473-3099(05)70239-5 
2. Smith AD, Bradley DJ, Smith V, Blaze M, Behrens RH, Chiodini PL et al. Imported malaria and high risk groups: observational study using UK surveillance data 1987-2006. $B M J$ 2008; 337: a120. doi:10.1136/bmj.a120

3. Cullen KA, Arguin PM. Malaria surveillance - United States, 2011. MMWR Surveill Summ 2013; 62(5): 1-17.

4. Slinko VG, Jarvinen KA, Beard FH, McCall BJ. Notifications of enteric diseases in returning travellers who visit friends and relative overseas: a call for action. Commun Dis Intell $Q$ Rep 2008; 32(3): 333-4.

5. Ward K, McAnulty J. Hepatitis A: who in NSW is most at risk of infection? N S W Public Health Bull 2008; 19(1-2): 32-5. doi:10.1071/NB07100

6. Fitzsimmons GJ, Wright P, Johansen CA, Whelan PI. National Arbovirus and Malaria Advisory Committee. Arboviral diseases and malaria in Australia, 2008-09: annual report of the National Arbovirus and Malaria Advisory Committee. Commun Dis Intell $Q$ Rep 2010; 34(3): 225-40.

7. Field V, Gautret P, Schlagenhauf P, Burchard GD, Caumes E, Jensenius $\mathrm{M}$ et al. Travel and migration associated infectious diseases morbidity in Europe, 2008. BMC Infect Dis 2010; 10: 330. doi:10.1186/1471-2334-10-330

8. Freedman DO, Weld LH, Kozarsky PE, Fisk T, Robins R, von Sonnenburg F et al. Spectrum of disease and relation to place of exposure among ill returned travellers. $N$ Engl J Med 2006; 354(2): 119-30. doi:10.1056/NEJMoa051331

9. O'Brien DP, Leder K, Matchett E, Brown GV, Torresi J. Illness in returned travellers and immigrants/refugees: the 6-year experience of two Australian infectious diseases units. $J$ Travel Med 2006; 13(3): 145-52. doi:10.1111/j.17088305.2006.00033.x

10. Health Protection Agency UK. Foreign travel-associated illness - a focus on those visiting friends and relatives: 2008 report. Available at: http://www.hpa.org.uk/Publications/ InfectiousDiseases/TravelHealth/0812Foreigntravelassociated illness/ (Cited 14 March 2014).

11. Leder K, Tong S, Weld L, Kain KC, Wilder-Smith A, von Sonnenburg F et al. Illness in travellers visiting friends and relatives: a review of the GeoSentinel surveillance network. Clin Infect Dis 2006; 43(9): 1185-93. doi:10.1086/ 507893

12. Australian Bureau of Statistics. Overseas Arrivals and Departures - Customised Data Report. 12 March 2012.

13. Communicable Diseases Branch. NSW Notifiable Diseases Manual. Sydney: NSW Health; 2008.

14. World Bank Country and Lending Groups. Available at: http://data.worldbank.org/about/country-classifications/ country-and-lending-groups (Cited 16 April 2014).

15. Australian Bureau of Statistics. Australian Demographic Statistics. Publication No 3101.0.

16. Australian Bureau of Statistics. Overseas Arrivals and Departures, Australia, Dec 2011. Cat No 3401.0.

17. Gunaratnam P, Tobin S, Seale H, Musto J. Typhoid fever, NSW, 2005-2011. N S W Public Health Bull 2013; 24(2): 87-91. doi:10.1071/NB12125

18. Angell SY, Cetron MS. Health disparities among travellers visiting friends and relatives abroad. Ann Intern Med 2005; 142(1): 67-72. doi:10.7326/0003-4819-142-1-20050104000013

19. Bacaner N, Stauffer B, Boulware DR, Walker PF, Keystone JS. Travel medicine considerations for North American immigrants visiting friends and relatives. JAMA 2004; 291(23): 2856-64. doi:10.1001/jama.291.23.2856

20. Fulford M, Keyston JS. Health risks associated with visiting friends and relatives in developing countries. Curr Infect Dis Rep 2005; 7(1): 48-53. doi:10.1007/s11908-005-0023-z

21. Zwar N, Streeton CL. Travel Health Advisory Group. Pretravel advice and hepatitis A immunization among Australian travellers. J Travel Med 2007; 14(1): 31-6. doi:10.1111/j.17088305.2006.00088.x

22. National Health and Medical Research Council. The Australian Immunisation Handbook. 9th ed. Canberra: Australian Government Department of Health and Ageing; 2008.

23. NSW Health. Infectious Diseases. Available at: http:// www.health.nsw.gov.au/infectious/Pages/default.aspx (Cited 12 March 2014). 